\title{
During twenty years of Cisplatin-based therapy the face of nonseminomatous testicular germ cell tumors is still changing: an evaluation of presentation, management, predictive factors and survival
}

\author{
Julia Heinzelbecker, Michaela Katzmarzik, Christel Weiss, Lutz Trojan, Axel Haecker
}

Department of Urology, University Medical Center Mannheim, Medical Faculty Mannheim, University of Heidelberg (JH, AH), Mannheim; Department for Anaesthesiology and Operative Intensive Care Medicine, Cologne-Merheim Medical Center (MK), University Witten/Herdecke; Institute of Medical Statistics and Biometry, Medical Faculty Mannheim, University of Heidelberg (CW), Mannheim and Department of Urology, University Medical Centre Göttingen (LT), Georg-August University, Göttingen, Germany

\section{ABSTRACT}

Purpose: To assess the changing presentation and treatment of nonseminomatous testicular germ cell tumors (NSGCT) and to investigate predictive factors for the status of metastasis at diagnosis and on relapse and death.

Materials and Methods: Retrospective record review of 147 patients that underwent inguinal orchiectomy from 1987-2007. Follow-up data was available for 102 patients (median follow-up: 80 months (0-243); 96 patients alive).

Results: Mean patients age increased $(\mathrm{p}=0.015)$ and more patients were diagnosed in clinical stage I (CSI) ( $p=0.040)$. The fraction of yolk sac (YS) elements inclined ( $p=0.030)$ and pT2 tumors increased ( $<<0.001$ ). Retroperitoneal lymph node dissection (RPLND) declined whereas more patients were treated with chemotherapy $(p<0.001 ; p=0.004)$. There was an increase in relapse free (RFS) and cancer specific survival (CSS) due to an improvement in patients with disseminated disease $(p=0.014 ; p<0.001)$. The presence of YS and teratoma elements showed a reduction in the odds ratio (OR) for metastasis at diagnosis ( $p=0.002$, OR: $0.262 ; p=0.009$, OR: 0.428) whereas higher pT-stage was associated to their presence $(p=0.039)$. Patients with disseminated disease (CS $>$ I) showed a declined CSS compared to CSI patients $(p=0.055)$. The presence of YS elements was associated to an improved RFS ( $\mathrm{p}=0.038)$.

Conclusions: In our single institution study the face of NSGCT markedly changed over 20 years even after the introduction of Cisplatin-based chemotherapy. These changes were accompanied by an improvement in RFS and CSS. When dealing with NSGCT patients such observations now and in the future should be taken into account.

\section{ARTICLE INFO}

\section{Key words:}

ECBC protocol; Nonseminomatous germ cell tumor; Survival; Recurrence

Int Braz J Urol. 2013; 39: 10-21

Submitted for publication:

August 03, 2012

Accepted after revision: January 10, 2012

\section{INTRODUCTION}

Testicular cancer (TC) is the most common malignancy in young men and most of the pa- tients are diagnosed in early tumor stages. With the introduction of Cisplatin-based chemotherapy in the 1970s TC became an excellently curable disease. However, its etiology and pathogenesis 
remain widely unknown (1). Thus observational changes in the presentation of the diseases as well as changes in treatment regimens and survival may lead to a better understanding of the disease itself. Worldwide, a growing incidence has been described and it has already been pointed out that the presentation of the disease is changing $(2,3)$.

The aim of the present study was to evaluate nonseminomatous testicular cancer (NSGCT) for possible changes in presentation and treatment that occurred after the introduction of chemotherapy. Furthermore, we evaluated our patient collective for predictive factors for metastasis at diagnosis as on relapse and death. Such observations will account for a better understanding of NSGCT presentation and may provide a forecast on future problems when dealing with these patients.

\section{MATERIALS AND METHODS}

Information was collected by retrospective record review of patients with histologically proven NSGCT that underwent radical orchiectomy between 1987 and 2007 at our institution. A total number of 147 patients were identified. Follow-up data of 102 patients (69\%) was available. Median follow-up was 80 months (0-243, patients alive: $\mathrm{n}=96(94 \%))$. For clinical and pathological patients' data see Table-1. For histopathological staging analysis the underlying TNM classifications were applied (4-6). Further staging analysis included CT-scan or X-ray and abdominal CT-scan. Division into clinical stages (CS) was performed according to the current TNM classification (7). For further evaluation the whole study period was divided into four periods (1987-1991; 1992-1996; 1997-2001; 2002-2007).

Statistical analysis was performed using SPSS (release 16.0) and SAS software (release 9.2). The changes along the study period were investigated by using Kruskal Wallis or $\mathrm{Chi}^{2}$ test as appropriate. One-way ANOVA analysis was used as a parametric test. Logistic regression was used as a multiple method in order to analyze the influence of possible prognostic parameters on the status of metastasis. Clinical outcome (RFS, CSS) was estimated by Kaplan-Meyer analysis and log rank testing. Statistical significance was defined as $\mathrm{p}<0.05$.

\section{RESULTS}

Changing presentation throughout the study periods

The clinical and pathological patients' data and treatment modalities in CSI according to the different study periods are listed in Table-2. Along the study period the total number of treated patients changed significantly $(p=0.037)$. Patients in the last studied period were significantly older compared to the first period (0.015). At the same time, a significant shift to pT2 and to more patients diagnosed in CSI was observed $(p<0.001 ; p$ $=0.040)$. Also, the presence of vascular invasion (VI) gained significant importance $(\mathrm{p}=0.030)$. Yolk sac (YS) elements within the histological condition of the tumor were found significantly more often in the last studied periods $(\mathrm{p}=0.011)$. In CSI retroperitoneal lymph node dissection (RPLND) lost importance in favor of chemotherapy $(p<0.001 ; p=0.004)$. The same development was observed for patients with disseminated disease ( $p<0.001$ each). The relapse free survival (RFS) tended to improve over the studied period ( $p=0.071)$. This was due to an improvement in patients with disseminated disease $(p=0.014)$. The cancer specific survival (CSS) significantly improved over the studied periods ( $p<0.001$ ), also due to an improvement in patients with disseminated disease (Table-3 and Figure-1).

\section{Predictive factors for CS}

Considering pT-stage, relative risk (OR) for CS > I was significantly elevated with higher pT-stage ( $\mathrm{p}=0.039)$. The OR for $\mathrm{pT} 3$ compared to pT1 tumors was 8.996 and for pT3 compared to pT2 tumors 8.329. In terms of histological condition, the OR for metastasis was significantly reduced in cases of teratoma ( $p=0.009$; OR: 0.428) and YS elements ( $p=0.002$; OR: 0.262). Other parameters as patients' age, tumor size or vascular invasion showed no association to the status of metastasis at diagnosis.

\section{Predictive factors for recurrence and survival}

Sixteen patients $(16 \%)$ relapsed and six patients $(6 \%)$ died. Median time to relapse was 18 (3-199) and median time to death ten months 
(0-84). 5-, 10- and 15-year relapse free survival (RFS) was 85\%, 80\% and 75\% respectively. 5-, 10and 15- year CSS was 95\%, 93\% and 93\% respectively. In terms of CSS patients in CS > I showed a reduced CSS compared to patients in CS I ( $p=$ 0.055). The histological condition of YS elements tended to be associated to an improved RFS ( $p=$ 0.087). The survival data of the patients is listed in Table-3.

\section{DISCUSSION}

Patients' age increased continuously over time. The presence of YS elements gained importance and more pT2 tumors were diagnosed. In terms of adjuvant therapy, RPLND lost importance in favor of chemotherapy. RFS and CSS improved over the study period due to an improvement in patients with disseminated disease. However, RFS in CS I patients declined. The presence of YS and teratoma elements showed a reduction in the relative risk (OR) for metastasis at diagnosis whereas higher pT-stage was associated to the presence of metastasis. Patients with disseminated disease showed a declined CSS compared to patients in CS I. The histological condition of YS elements tended to be associated to an improved RFS.

Although in our study a change of the number of NSGCT patients diagnosed over time was significant, a closer view uncovers that it actually remained stable. This finding is in contradiction to our recently published results about seminoma (8). However, it reflects the finding of several authors that the widely reported increase in TC incidence mainly affects seminomas (9). A change in prevalence factors over time, either in terms of differing risk factors for seminoma and NSGCT or of a relation between the intensity of risk factor exposure and the histological type of TC, might account on that (9). Over time, more of our NSGCT patients presented in CSI as reported earlier by other study groups $(10,11)$. The similar results in seminoma favor the hypothesis of an improved awareness of TC as well as an improved accessibility to health care institutions (12). Additionally it, was discussed that NSGCT develops out of seminoma. Thus, a diagnosis of TC in earlier tumor stages would result in an increase of semi- noma (13). We found a significant increase in patients' age between the periods of 1987-1991 and 2002-2007. To the best of our knowledge, no such a development has been reported earlier. In contradiction to our observation, Cooper et al. in their 20 year review did not report on a change in patients' age at diagnosis (10). As we examined only a small patient collective this observation has to be investigated in other study cohorts as it could cover a hint on the etiology of NSGCT. In the last studied period we noticed an increase in histopathological diagnosis of VI. VI has long since been described as the most important predictive factor for occult metastasis in NSGCT (14). However, only in 1997 it was implemented in the TNM classification causing a change from pT1 to pT2 tumor stages (5). Simultaneously, we found a continuous increase in pT2 tumors accompanied by a decrease in pT1 and pT3 tumor stages. An increase in the diagnosis of VI from 2002-2007 might be determined by a change in attention paid by pathologists. Nevertheless, such changes would have rather been suspected earlier in the period of 1997-2001. Thus, changes in the pathogenesis of the disease itself might also be a possible explanation. We noticed a significant increase in fractions of YS elements especially after 1997. To our knowledge so far there have not been any such reports concerning adult testicular NSGCT. However, for pediatric germ cell tumors, a growing incidence of YS tumors has been reported. As an increase in YS tumors was noticed especially in industrialized regions, an association with environmental factors was assumed $(15,16)$. Over the studied period, significantly more patients underwent adjuvant chemotherapy and especially since 1997 we noticed a decline in RPLND. According to the current English literature, only little data on changes over time in adjuvant treatment modalities for Europe exist. For Spain, Molina Saera et al. reported on an increase in the use of chemotherapy, however no data on RPLND was provided (17). For America, Steele and co-workers reported on a trend towards an increasing frequency of RPLND from 1985-1996 (3). However, Cooper et al. in their military database study on NSGCT patients reported on a decline in RPLND during their last examined studied periods (1998-2007: 62\%; 1994-1997: 
Table 1 - Characteristics of patients with nonseminomatous testicular cancer.

\begin{tabular}{|c|c|c|}
\hline Characteristics & Number of contributing patients & \\
\hline Mean patients' age, years \pm SD & 147 & $30.7 \pm 8.4$ \\
\hline Histological condition, $\mathrm{n}(\%)$ & 129 & - \\
\hline Seminomatous elements & - & $55(43)$ \\
\hline Embryonal carcinoma elements & - & $101(78)$ \\
\hline Yolk sac elements & - & $30(23)$ \\
\hline Teratomatous elements & - & $71(55)$ \\
\hline Choriocarcinoma elements & - & $21(16)$ \\
\hline Mean tumor size, $\mathrm{cm} \pm \mathrm{SD}$ & 130 & $3.8 \pm 2.2$ \\
\hline Presence of small vessel invasion, $\mathrm{n}(\%)$ & 140 & - \\
\hline Yes & - & $56(40)$ \\
\hline pT stage, n (\%) & 142 & - \\
\hline pT1 & - & $85(60)$ \\
\hline pT2 & - & $43(30)$ \\
\hline pT3 & - & $14(10)$ \\
\hline pT4 & - & $0(0)$ \\
\hline Tumor markers & 147 & - \\
\hline Median AFP, ng/mL (range) & 139 & $69(1-37759)$ \\
\hline Median $\beta-H C G, n g / m L$ (range) & 141 & $22(0.01-450370)$ \\
\hline Median LDH, U/I (range) & 95 & $226(135-4277)$ \\
\hline Clinical stage, $\mathrm{n}(\%)$ & 147 & - \\
\hline I & - & $81(55)$ \\
\hline$\|$ & - & $44(30)$ \\
\hline III & - & $22(15)$ \\
\hline$>1$ & - & $66(45)$ \\
\hline IGCCCG classification & 64 & - \\
\hline Good & - & $40(63)$ \\
\hline Intermediate & - & $14(22)$ \\
\hline
\end{tabular}


CONTINUATION

\begin{tabular}{|c|c|c|}
\hline Characteristics & Number of contributing patients & \\
\hline Poor & - & $10(16)$ \\
\hline Adjuvant treatment, $\mathrm{n}(\%)$ & - & - \\
\hline CSI & 78 & - \\
\hline Surveillance & - & $15(19)$ \\
\hline Chemotherapy & - & $33(42)$ \\
\hline RPLND & - & $29(37)$ \\
\hline Radiation therapy & - & $1(1)$ \\
\hline CS II & 43 & - \\
\hline Chemotherapy & - & $22(51)$ \\
\hline RPLND & - & $2(5)$ \\
\hline Chemotherapy + RPLND & - & $19(44)$ \\
\hline CS III & 21 & - \\
\hline Chemotherapy & - & $13(62)$ \\
\hline Chemotherapy + surgery* & - & $8(38)$ \\
\hline Median follow-Up, months (range) & 102 & $80(0-243)$ \\
\hline Median time to relapse, months (range) & - & $18(3-199)$ \\
\hline Median time to death, months (range) & - & $10(0-84)$ \\
\hline Relapse, n (\%) & - & $16(16)$ \\
\hline Death, n (\%) & - & $6(6)$ \\
\hline Patients alive, $n(\%)$ & - & $96(94)$ \\
\hline
\end{tabular}

SD = standard deviation; $\mathbf{n} . \mathbf{e} .=$ not evaluable; $\mathbf{A F P}=$ alpha-fetoprotein; $\boldsymbol{\beta}$-HCG = human chorionic gonadotropin; $\mathbf{L D H}=$ Lactate dehydrogenase; UPN = upper limit of normal; $\mathbf{C S}$ = Clinical stage; IGCCCG = International germ cell cancer consensus group; $\mathbf{R P L N D}=$ Retroperitoneal lymph node dissection; *surgery includes RPLND and residual tumor resection 


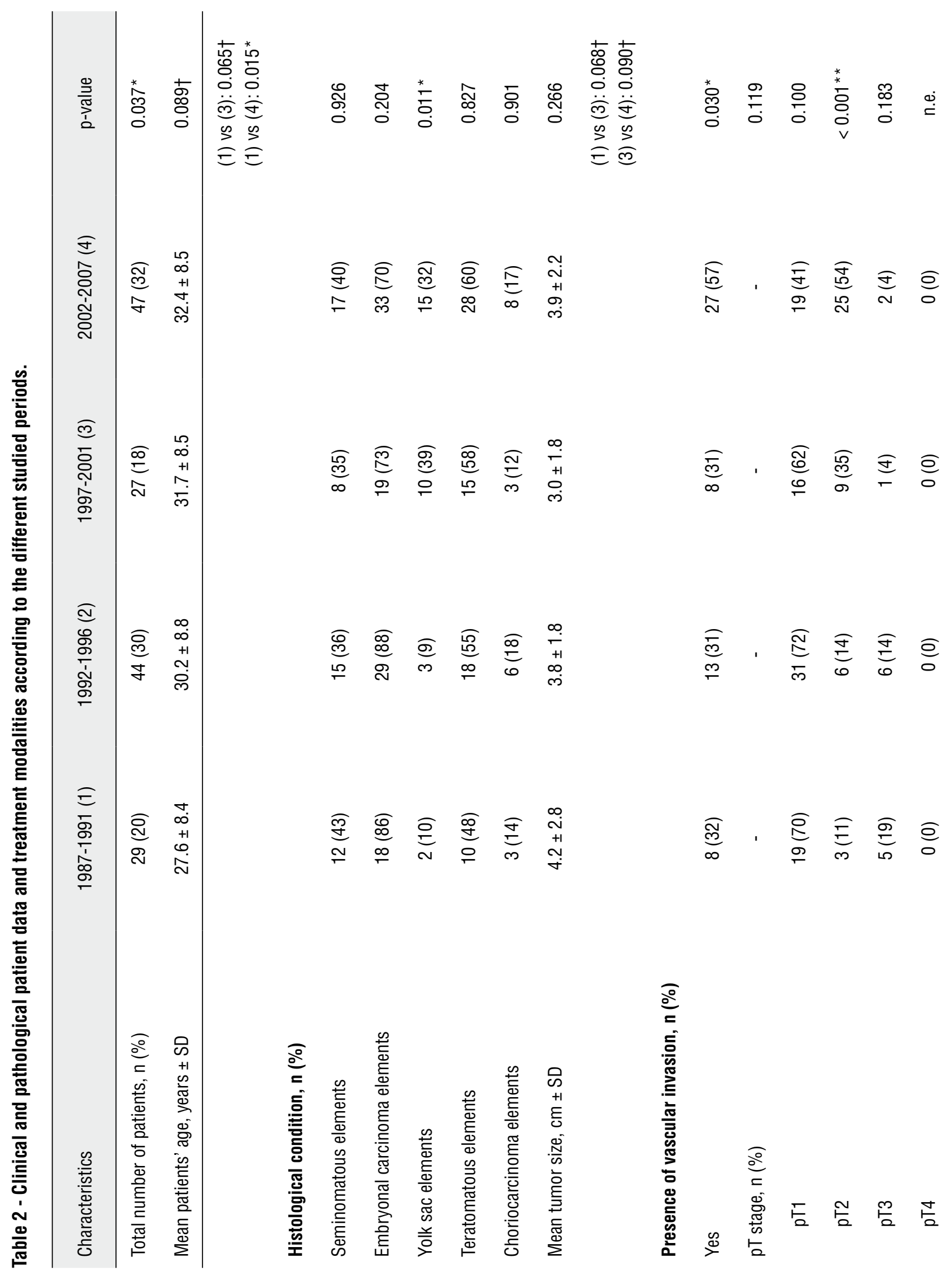




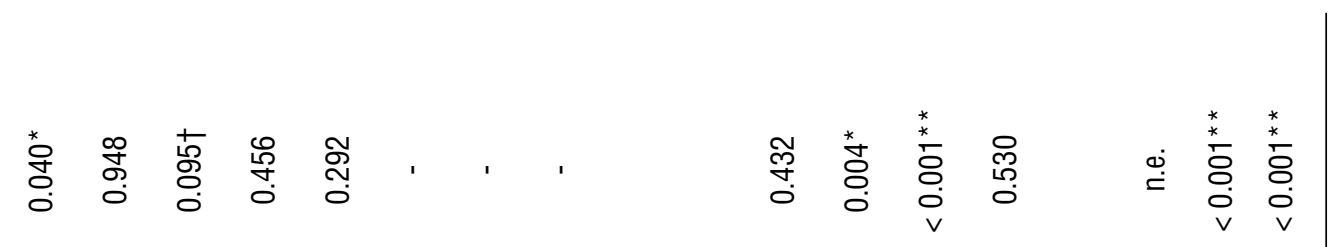

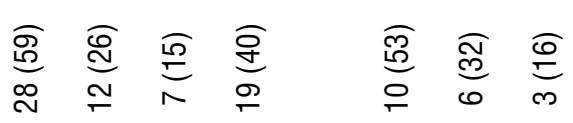

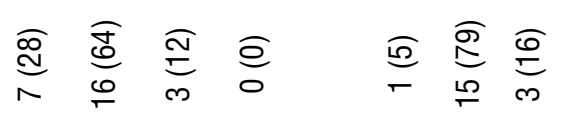

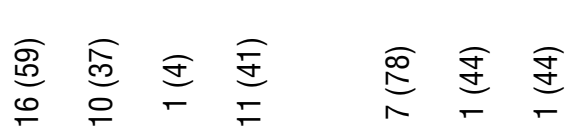

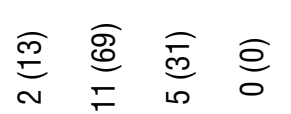

$\underset{0}{\stackrel{\sigma}{\sigma} \underset{\sigma}{\sigma}}$

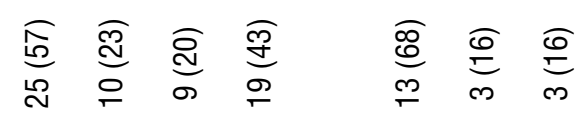

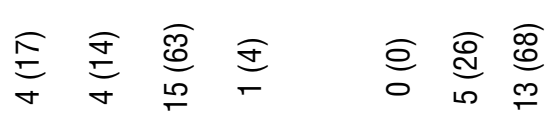

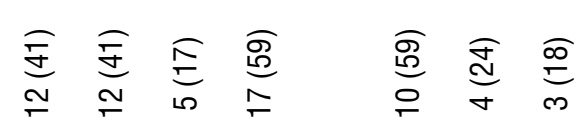

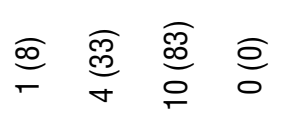

ब음
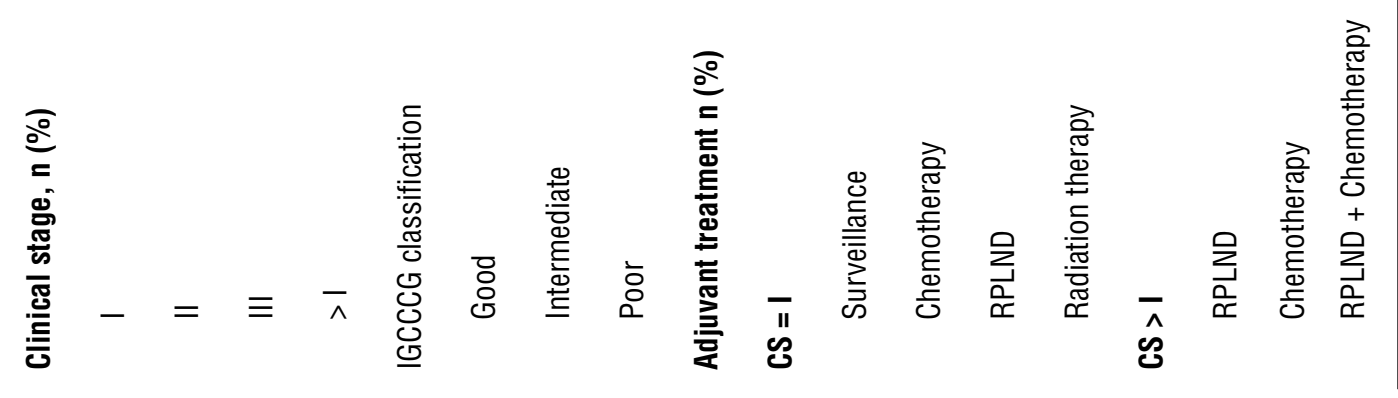

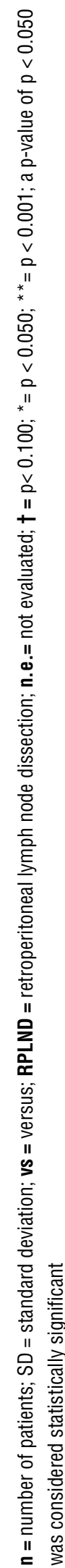




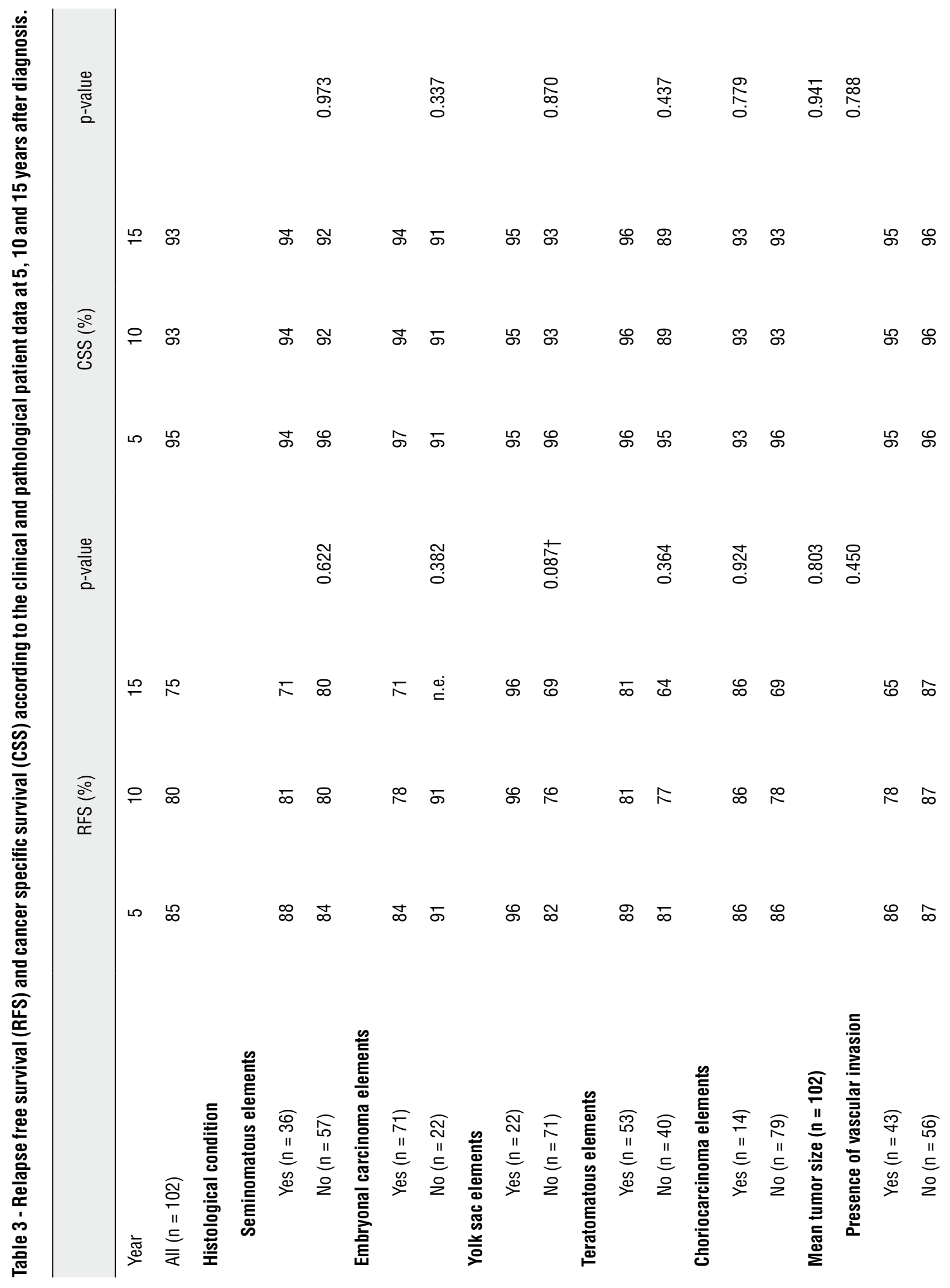




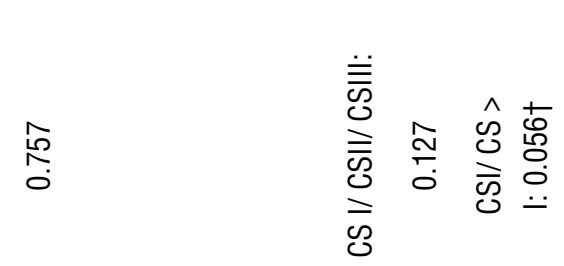

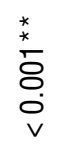

$$
\begin{aligned}
& \text { ণ్ర్ర } \\
& \text { চ } \stackrel{\oplus}{\check{~}} \text { ○ } \\
& \text { கு }
\end{aligned}
$$

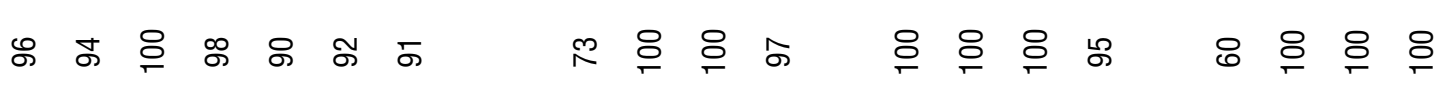

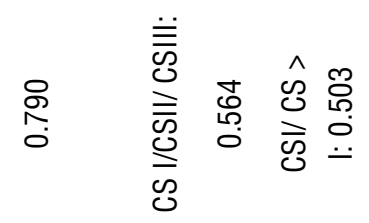

$$
\begin{aligned}
& \underset{\substack{\leftarrow \\
0}}{\stackrel{\hbar}{0}}
\end{aligned}
$$

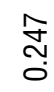

$$
\begin{aligned}
& \frac{*}{0}
\end{aligned}
$$

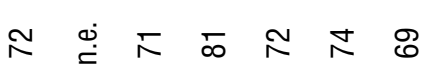

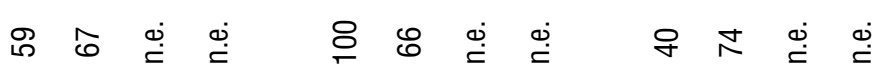

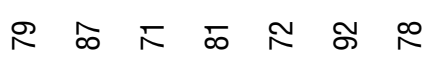

$$
\begin{aligned}
& \text { is } \\
& \text { 응 ஜ }
\end{aligned}
$$

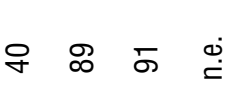

$$
\begin{aligned}
& \text { œ }
\end{aligned}
$$

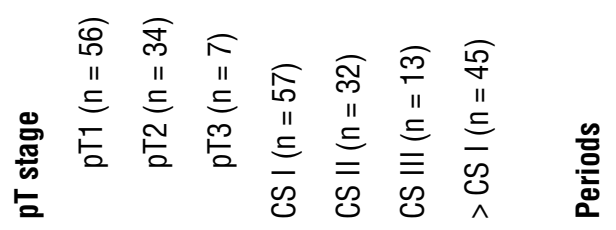

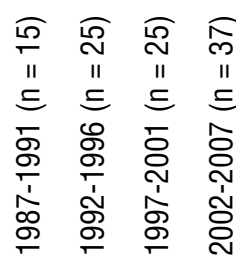

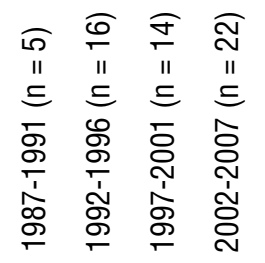

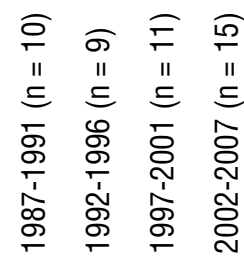

$$
\begin{aligned}
& \text { "I } \\
& \text { त्र }
\end{aligned}
$$

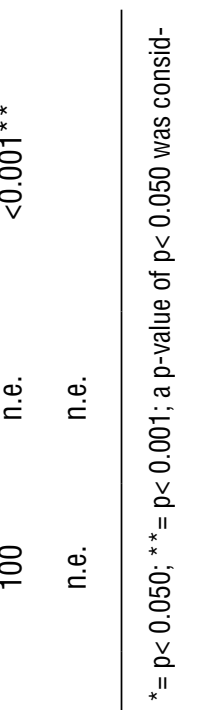


Figure 1 - Cancer specific survival curves of metastasized NSGCT patients according to the different studied groups (1987-1991; 1992-1996; 1997-2001; 2002-2007).

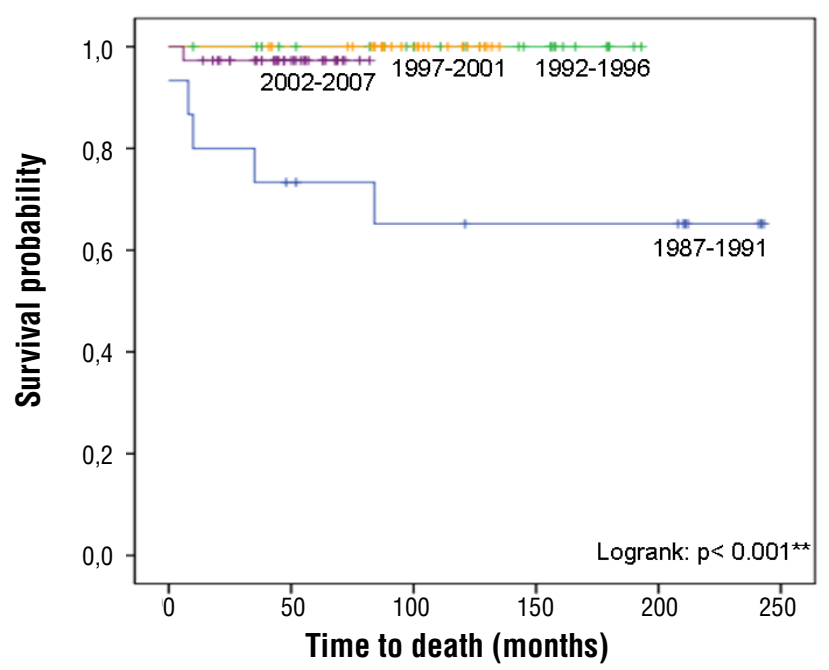

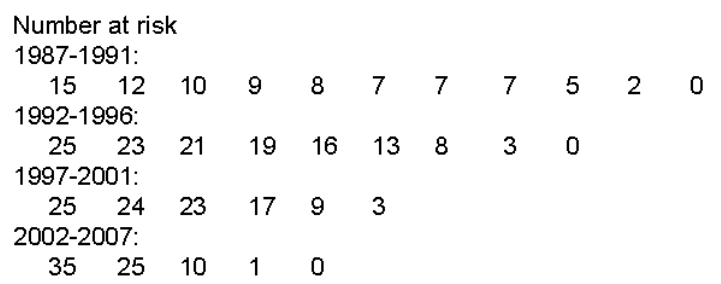

$88 \%$ ) (10). An upcoming focus on life quality might be a possible explanation for such observations. Nevertheless, $62 \%$ of performed RPLND is still high compared to our results of $12-31 \%$. Thus, regional as institutional circumstances might also play a role. The latest European guidelines on NSGCT nowadays give explicit recommendations, classifying RPLND as rather second or third treatment of choice (18). However, in the EAU guideline of 2001 yet there was a clear recommendation for RPLND besides surveillance and chemotherapy (19). Our data demonstrate that treatment changes in clinical practice took place even earlier. A trend towards more surveillance, the nowadays standard treatment option for low risk NSGCT patients, was not observed in our study collective (18). In our patient collective RFS in disseminated disease continuously improved over time. We believe that this change in RFS is mainly due to a historical policy of RPLND in CS IIA/B patients in the past that changed to a policy of primary chemotherapy in CS IIA/B NSGCT patients after 1996. The preferred treatment regimen in CS IIA/B patients still remains controversial as for both chemotherapy and RPLND survival rates of more than 95\% have been described $(20,21)$. Stephenson et al. reported on an increase in RFS in their CS IIA/B patient collective after 1999 and hypothesized that this was due to a more adequate patient selection according to established parameters of progression as elevated tumor markers or adenopathy larger than $2 \mathrm{~cm}$ (22). The current EAU guideline on NSGCT recommend RPLND in CS IIA/B patients only in case of negative markers (18). However, at the same time there was an incline in RFS of CS I patients. Most probably this is due to the higher rate of surveillance regimens after 1991 that will always cause a certain amount of relapses. CSS in our patient collective improved especially since 1992. Sonneveld et al. reported on a significant improvement in the survival rate of their metastasized NSGCT patients from 1977-1986 compared to 1987-1996 (23). Data of the Roland-Koch Institute in Germany report on a first incline in survival rates in the 1970s due to the introduction of Cisplatin based chemotherapy followed by a further incline since the 1980 s with relative 5 year survival rates increasing from $80 \%$ to $95 \%$ (24). In our institution the improvement in CSS was mainly due to a harsh incline in events of death after 1992. We found a reduction in the relative risk for metastases at diagnosis in case of the presence of teratoma and YS elements. This finding is in concordance to a study of Klepp et al. of a CSI patient collective, undergoing RPLND. Herein they reported that the absence of teratoma or YS elements was a predictor for retroperitoneal metastases (25). Other studies reported on a higher rate of metastatic disease in tumors containing less than 50\% of teratoma elements (26). In our study collective higher pT-stage was associated with the presence of metastasis at diagnosis. Nicolai and colleagues created a model for the prediction of nodal metastasis at diagnosis. However, t-stage did not serve as a predictor, in contrary VI served as a reliable predictor (27). We found no association between VI and the status of metastasis. We report on a 5-, 
10- and 15- year CSS of 95\%, 93\% and 93\%, respectively. This is in concordance to other results reported by Sokoloff and colleagues on their American study collective from 1975-2001 with a 96\% survival rate. However, no discrimination between NSGCT and seminoma was made (28). Compared to Europe such CSS rates even exceed the upper limit of reported data, ranging for NSGCT from $47 \%$ - 90\%. Yet this data only comprised an early studied period from 1987-1992 and only an excerpt of European countries was included (29). Sonneveld et al. report on a 10 -year CSS of $82 \%$ for NSGCT. However, their study period comprises an early time period from 1977 to 1996, too (23). The Roland Koch Institute of Germany delivered latest relative 5-year survival rates of up to 95\% (24). Thus, our CSS rates are very good. 16\% of our NSGCT patients relapsed and 5-, 10- and 15year RFS were $85 \%, 80 \%$ and 75\%, respectively. For Europe a relapse rate of 12\% (0-34\%) was reported (29). In terms of CSS, patients with metastasized disease (CS > I) showed a worse survival compared to patients in CS I. Hence, these results underline the prognostic value of the TNM classification. The histological condition of YS elements was associated with an improved RFS. Other study groups also reported on the absence of YS elements being associated to a reduction in relapse (30). Our study is limited by its retrospective study character that leads to a considerable lack of data concerning histopathology and follow-up data. Furthermore no re-evaluation by application of the recent TNM-classification took place. With TC being a disease of excellent CSS there is a further limitation by the small number of events especially in terms of death. Therefore, a multivariate analysis was not performed. The data here presented are restricted to a single-center population. Thus, affirmations above population trends cannot be made.

The remarkable changes in RFS and CSS for both stage I and disseminated disease after the first five year period reflect a change in treatment policies that took place all over Europe. With the excellent survival data provided for NSGCT, patients in early stages of the disease make high demands on the form of treatment they will choose. Clinical trials have already proofed the possibili- ties of surveillance regimens. At the same time the importance of RPLND has declined.

\section{CONCLUSIONS}

Detecting patients at high risk of relapse and clearly discriminating them from low-risk otherwise overtreated patients is as urgent as ever. The data of the last decades shows that a further improvement in CSS is possible even after the introduction of Cisplatin-based chemotherapy.

\section{ABBREVIATIONS}

NSGCT: Nonseminomatous testicular germ cell tumor

CSI: Clinical stage I

YS: Yolk sac

RPLND: Retroperitoneal lymph node dissection

RFS: Relapse free survival

CSS: Cancer specific survival

OR: Odds ratio

CS>I: Disseminated disease

TC: Testicular cancer

\section{CONFLICT OF INTEREST}

None declared.

\section{REFERENCES}

1. Meeks JJ, Sheinfeld J, Eggener SE: Environmental toxicology of testicular cancer. Urol Oncol. 2012; 30: 212-5.

2. Power DA, Brown RS, Brock CS, Payne HA, Majeed A, Babb P: Trends in testicular carcinoma in England and Wales, 1971-99. BJU Int. 2001; 87: 361-5.

3. Steele GS, Richie JP, Stewart AK, Menck HR: The National Cancer Data Base report on patterns of care for testicular carcinoma, 1985-1996. Cancer. 1999; 86: 2171-83.

4. WHO: International histological classification of tumours. 2nd ed. Geneva: WHO; 1981-1999.

5. Sobin LH, Wittekind C: UICC TNM Classification of malignant tumours. 5th ed. New York: Wiley \& Sons. 1997.

6. Sobin LH: Wittekind UICC TNM Classification of malignant tumours. C. UICC TNM classification of malignant tumours. 6th ed. New York: Wiley \& Sons. 2002.

7. Sobin LH, Gospodariwicz M, Wittekind C: TNM classification of malignant tumors. 7 ed. New York: Wiley-Blackwell. 2009. 
8. Heinzelbecker J, Katzmarzik M, Weiss C, Trojan L, Michel MS, Haecker A: Changes of stage, predictive factors and adjuvant treatment modalities in seminomatous testicular cancer from 1987 to 2007 and their impact on the status of metastasis, recurrence-free and overall survival: a singlecenter analysis. Urol Int. 2011; 87: 282-7.

9. McGlynn KA, Devesa SS, Sigurdson AJ, Brown LM, Tsao L, Tarone RE: Trends in the incidence of testicular germ cell tumors in the United States. Cancer. 2003; 97: 63-70.

10. Cooper DE, L'esperance JO, Christman MS, Auge BK: Testis cancer: a 20-year epidemiological review of the experience at a regional military medical facility. J Urol. 2008; 180: 577-81; discussion 581-2.

11. Sonneveld DJ, Hoekstra HJ, Van Der Graaf WT, Sluiter WJ, Schraffordt Koops H, Sleijfer DT: The changing distribution of stage in nonseminomatous testicular germ cell tumours, from 1977 to 1996. BJU Int. 1999; 84: 68-74.

12. Powles TB, Bhardwa J, Shamash J, Mandalia S, Oliver T: The changing presentation of germ cell tumours of the testis between 1983 and 2002. BJU Int. 2005; 95: 1197-200.

13. Oliver RT, Leahy M, Ong J: Combined seminoma/non-seminoma should be considered as intermediate grade germ cell cancer (GCC). Eur J Cancer. 1995; 31A: 1392-4.

14. Kratzik C, Höltt W, Albrecht W, Pont J, Zielinski CH, Breindl E, et al.: Risk adapted management for NSGCT stage 1 - longterm results of a multicenter study. J Urol. 1996; 157: 547A.

15. Muir KR, Parkes SE, Lawson S, Thomas AK, Cameron AH, Mann JR: Changing incidence and geographical distribution of malignant paediatric germ cell tumours in the West Midlands Health Authority region, 1957-92. Br J Cancer. 1995; 72: 219-23.

16. Birch JM, Marsden HB, Swindell R: Pre-natal factors in the origin of germ cell tumours of childhood. Carcinogenesis. 1982; 3: 75-80.

17. Molina Saera J, Aparicio Urtasun J, Díaz Beveridge R, Palomar Abad L, Giménez Ortiz A, Ponce Lorenzo J, et al.: Epidemiological pattern and time trends in testicular germ-cell tumors: a single institution 20-year experience. Clin Transl Oncol. 2006; 8: 588-93.

18. Albers P, Albrecht W, Algaba F, Bokemeyer C, Cohn-Cedermark $\mathrm{G}$, Fizazi $\mathrm{K}$, et al.: $\mathrm{EAU}$ guidelines on testicular cancer: 2011 update. Eur Urol. 2011; 60: 304-19.

19. Laguna MP, Pizzocaro G, Klepp O, Algaba F, Kisbenedek L, Leiva 0, et al.: EAU guidelines on testicular cancer. Eur Urol. 2001; 40: 102-10.

20. Donohue JP, Thornhill JA, Foster RS, Rowland RG, Bihrle $R$ : Clinical stage $B$ non-seminomatous germ cell testis cancer: the Indiana University experience (1965-1989) using routine primary retroperitoneal lymph node dissection. Eur J Cancer. 1995; 31A: 1599-604.
21. Weissbach L, Bussar-Maatz R, Flechtner H, Pichlmeier U, Hartmann M, Keller L: RPLND or primary chemotherapy in clinical stage IIA/B nonseminomatous germ cell tumors? Results of a prospective multicenter trial including quality of life assessment. Eur Urol. 2000; 37: 582-94.

22. Stephenson AJ, Bosl GJ, Motzer RJ, Bajorin DF, Stasi JP, Sheinfeld J: Nonrandomized comparison of primary chemotherapy and retroperitoneal lymph node dissection for clinical stage IIA and IIB nonseminomatous germ cell testicular cancer. J Clin Oncol. 2007; 25: 5597-602.

23. Sonneveld DJ, Hoekstra HJ, van der Graaf WT, Sluiter WJ, Mulder NH, Willemse PH, et al.: Improved long term survival of patients with metastatic nonseminomatous testicular germ cell carcinoma in relation to prognostic classification systems during the cisplatin era. Cancer. 2001; 91: 1304-15.

24. Bertz J, Dahm S, Haberland J, Kraywinkel K, Kurth BM, Wolf U: Verbreitung von Krebserkrankungen in Deutschland. Entwicklung der Prävalenzen zwischen 1990 und 2010. Beiträge zur Gesundheitsberichterstattung des Bundes. Berlin. RKI. 2010.

25. Klepp 0, Olsson AM, Henrikson H, Aass N, Dahl 0, Stenwig $A E$, et al.: Prognostic factors in clinical stage I nonseminomatous germ cell tumors of the testis: multivariate analysis of a prospective multicenter study. Swedish-Norwegian Testicular Cancer Group. J Clin Oncol. 1990; 8: 509-18.

26. Guney S, Guney N, Sonmez NC, Ergenekon E: Risk-adapted management for patients with clinical stage I non-seminomatous germ cell tumour of the testis. Med Oncol. 2009; 26: 136-42.

27. Nicolai N, Miceli R, Artusi R, Piva L, Pizzocaro G, Salvioni R: A simple model for predicting nodal metastasis in patients with clinical stage I nonseminomatous germ cell testicular tumors undergoing retroperitoneal lymph node dissection only. Urol. 2004; 171: 172-6.

28. Sokoloff MH, Joyce GF, Wise M, Urologic Diseases in America Project: Testis cancer. J Urol. 2007; 177: 2030-41.

29. Sant M, Aareleid T, Artioli ME, Berrino F, Coebergh JW, Colonna M, et al.: Ten-year survival and risk of relapse for testicular cancer: a EUROCARE high resolution study. Eur J Cancer. 2007; 43: 585-92.

30. Freedman LS, Parkinson MC, Jones WG, Oliver RT, Peckham MJ, Read G, et al.: Histopathology in the prediction of relapse of patients with stage I testicular teratoma treated by orchidectomy alone. Lancet. 1987; 2: 294-8.

Correspondence address: Dr. Julia Heinzelbecker Department of Urology University Medical Center Mannheim Theodor-Kutzer Ufer 1-3, 68157 Mannheim, Germany Tel.: +496213831620

E-mail: julia.heinzelbecker@umm.de 